\title{
perifèria
}

Número 20(2), diciembre 2015

www.periferia.name

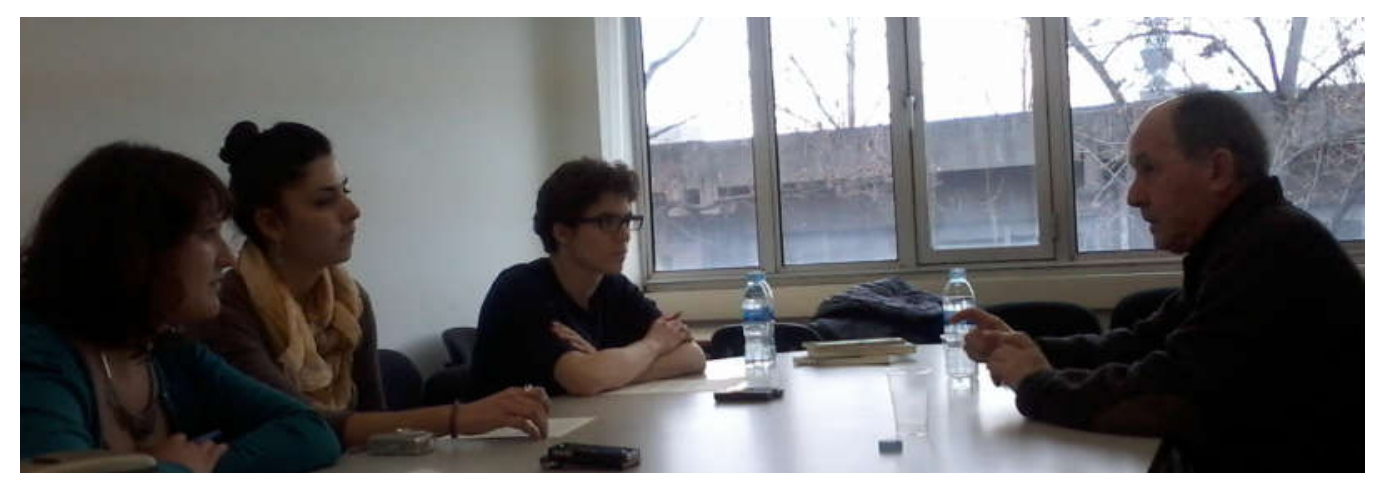

\section{L'etnografia com a camí: entrevista a Joan Frigolé}

\section{Montserrat Clua Fainé1 - Universitat Autònoma de Barcelona²}

DOI: http://dx.doi.org/10.5565/rev/periferia.497

\section{Resum}

El 28 de març de 2014 es celebrà a la Universitat de Barcelona un acte d'homenatge al Catedràtic Joan Frigolé en motiu de la seva jubilació. ${ }^{3}$ Un mes abans el Projecte Entrevistes tenia el privilegi d'entrevistar-lo. En la conversa el Dr.Frigolé ens va explicar com va arribar a I'antropologia a través de Claudi Esteva, els seus inicis assemblearis a la universitat franquista i la fundació de l'ICA. En el seu relat es mostra la importància que van tenir les experiències etnogràfiques en la delimitació dels temes que ha estudiat, mostrant el fil conductor que va des del treball de camp a Calasparra (Múrcia), fins a les trementinaires i el procés de patrimonialització a I'Alt Pirineu, passant per la institució de "llevarse a la novia", la relació entre antropologia i literatura aplicada al teatre de Lorca o l'antropologia del genocidi.

\footnotetext{
${ }^{1}$ Les preguntes les van fer els estudiants Pere Deulofeu, Davinia Campos i Aina Costa en el marc del Projecte Entrevistes que dirigeixo. L'entrevista es va realitzar a la UAB el 27 de febrer del 2014. Les fotografíes són de Montserrat Clua.

${ }^{2}$ Enviar correspondencia a: Montserrat.Clua@uab.cat

${ }^{3}$ Vegeu: http://www.ub.edu/ubtv/es/video/acte-d-homenatge-al-catedratic-joan-frigole
} 


\section{perifèria}

Número 20(2), diciembre 2015

www.periferia.name

Paraules clau: Joan Frigolé, Treball de camp, Calasparra, trementinaires, patrimoni

\section{Resumen}

El 28 de marzo de 2014 se celebró en la Universidad de Barcelona un acto de homenaje al Catedrático Joan Frigolé con motivo de su jubilación. ${ }^{3}$ Un mes antes el Projecte Entrevistes tenía el privilegio de entrevistarle. En la conversación el Dr.Frigolé nos explicó cómo llegó a la antropología a través de Claudi Esteva, sus inicios asamblearios en la universidad franquista y la fundación del ICA. En su relato se muestra la importancia que tuvieron las experiencias etnográficas en la delimitación de los temas que ha estudiado, mostrando el hilo conductor va que desde el trabajo de campo en Calasparra (Murcia), hasta las trementinaires y el proceso de patrimonialización en el Alto Pirineo, pasando por la institución de "llevarse a la novia", la relación entre antropología y literatura aplicada al teatro de Lorca o la antropología del genocidio.

Palabras clave: Joan Frigolé, Trabajo de campo, Calasparra, trementinaires, patrimonio

P: Primer de tot, molt bona tarda senyor Frigolé i moltes gràcies per atendre'ns en el projecte entrevistes.

F: No es mereixen.

P: Primer de tot voldríem començar per preguntar-li sobre els seus inicis en la disciplina. Pel què tenim entès, vostè va estudiar filosofia a la Universitat de Barcelona, on assistí a un curs d'antropologia cultural impartit per Claudi Esteva Fabregat. Què el va motivar a fer de l'antropologia la seva carrera?

F: [riu] Jo vaig estudiar Filosofia i Lletres i quan ja vaig acabar, vaig sentir a parlar de que havia arribat el doctor Claudi Esteva Fabregat a la Universitat de Barcelona. Potser ja feia un any o potser no, no ho sé, en aquest moment no ho tinc clar, però en tot cas ell acabava d'arribar feia poc a la 


\section{perifèria}

Número 20(2), diciembre 2015

www.periferia.name

Universitat de Barcelona. Havia estat exiliat a Mèxic, que és on va estudiar Antropologia Cultural i al tornar a Espanya es va quedar a Madrid (o el varen fer quedar a Madrid). Va estar en el departament d'Història i Antropologia o d'Arqueologia i Història d'Amèrica; i allà donava classes d'antropologia. I quan va venir a Barcelona va estar també en el Departament de Prehistòria i Arqueologia, perquè no hi havia cap departament d'antropologia. En aquella època l'antropologia apareixia en els plans d'estudis amb el nom d'Etnologia, entesa com una disciplina auxiliar de la prehistòria i de l'arqueologia. Per això en aquell departament de la Universitat de Barcelona hi havia matèries que es deien "Arqueologia $\mathrm{i}$ Etnologia" o a l'inversa. N'hi havia més d'una i I'Esteva va anar a parar allà. Llavors, jo vaig sentir a parlar d'ell i em vaig matricular - ja havent acabat d'estudiar filosofia-, en uns cursos que feia. Feia uns cursos generals: un curs d'Introducció a l'antropologia; també un curs que es deia Etnologia dels pobles primitius o Antropologia dels pobles primitius; i donava una Introducció a la sociologia, que en aquell moment no n'hi havia aquí, almenys a la Facultat de Geografia i Història. Va ser bastant casual, eh? A la vida hi ha algunes casualitats... [riu] Va ser a partir d'aquesta notícia, saps?

\section{P: Abans d'aquest curs no havia tingut cap altre contacte amb la disciplina?}

F: No, perquè no hi havia antropologia, no hi havia ningú que en fes. Bé, hi havia el Dr. Panyella, que estava en el Museu Etnològic d'allà Montjuic. No sé si tenia a veure amb la Universitat però de fet, a la nostra facultat, a la facultat de Filosofia i Lletres no hi havia cap matèria d'antropologia ni d'etnologia. A la carrera de filosofia, que eren tres anys d'especialitat, no 


\section{perifèria}

Número 20(2), diciembre 2015

www.periferia.name

n'hi havia. Hi havia un curs, una matèria de psicologia, però és I'única cosa així més o menys experimental, més o menys empírica, que hi havia. Lo altre, tot era... era bastant abstrús.

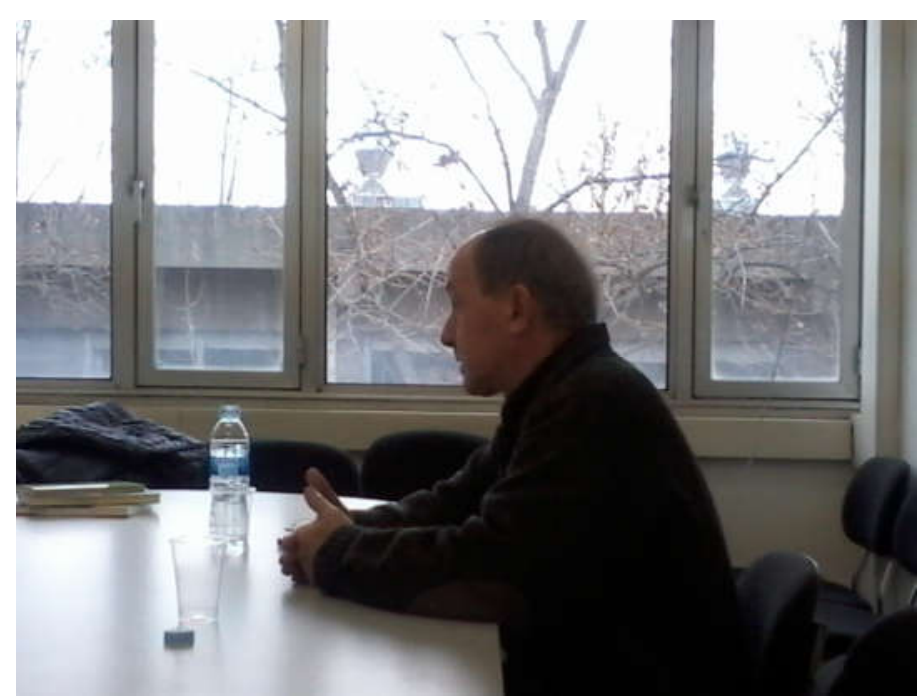

P: Als anys seixanta, durant la seva experiència universitària, vostè era delegat de la Facultat de Filosofia i fou un dels fundadors del Sindicat Democràtic d'Estudiants de la UB (SDEUB) al 1966?

F: Bé, tant com fundador... Jo vaig ser membre d'aquest sindicat [riu]. Vaig arribar a ser delegat de la meva facultat, perquè hi havia una estructura a I'organització del Sindicat Democràtic de la Universitat de Barcelona a nivell de cada curs, després a nivell de facultat i a nivell de tot el districte. Hi havia delegats de curs, delegats de la facultat..., etc. I aquests delegats de la facultat eren els que formaven la Junta de Delegats de la Universitat. Hi vaig estar-hi un temps, sí. 


\section{perifèria}

Número 20(2), diciembre 2015

www.periferia.name

\section{P: Ens preguntàvem com era estudiar a l'època franquista i com va arribar a formar part dels moviments clandestins, com era formar- ne part?}

F: A veure,... Jo vaig començar a estudiar a Barcelona a l'any 1964-65 i jo de política no en tenia ni idea. Ho explico en un text que he escrit com a introducció per un llibre que editarem, que és la primera part del meu diari de camp, l'etnografia que vaig fer a Calasparra (Múrcia). ${ }^{4}$ Allà explico una mica els meus orígens. Els meus pares eren uns petits pagesos, jo vaig passar per un seminari i vaig sortir-ne quan tenia uns divuit anys. I això va ser l'equivalent del Batxillerat, sinó segurament no hauria estudiat. Llavors vaig venir a Barcelona però no tenia idea de política en aquesta època. $\mathrm{Ni}$ al seminari ni al meu poble no se'n parlava d'aquestes coses. I el primer any, el 1964-65, va ser un any, diguem-ne tranquil, encara la política no es va destacar molt, la mobilització dels estudiants no va ser gaire important. Però ja va començar. Perquè els estudiants estaven en el sindicat. A Espanya hi havia la Central Nacional Sindicalista, la CNS, que era... diguemne que era un sindicat únic, no? I estava basat en el principi del corporativisme; és a dir, que els jornalers, petits pagesos i els grans propietaris estaven dintre de la CNS; per exemple, en la Hermandad de Labradores y Ganaderos, que era una de les especificacions d'aquesta central. Uns estaven a la secció social i els altres a la secció econòmica, no? I llavors a nivell universitari hi havia un sindicat que es deia SEU, Sindicato

\footnotetext{
4 Joan Frigolé Reixach, Las conversaciones y los días en Calasparra. Diario etnográfico 1971-1974 (Alzira, València: Neopàtria, 2015)
} 


\section{perifèria}

Número 20(2), diciembre 2015

www.periferia.name

Español Universitario. Allà hi érem tots. Llavors, a l'any 64-65 vam començar a trencar amb el SEU. Ja hi va haver-hi algunes assemblees, va venir algun representant exterior, va venir un xicot belga-francès i va haver-hi alguna assemblea. I la consigna era trencar amb el SEU, que era I'organisme corporatiu. I potser no va començar la repressió però a mesura que es va voler substituir pel SDEUB, per aquest sindicat propi, llavors ja va començar la repressió. El 65-66 va ser un any ja de molta activitat política, de moltes mobilitzacions i de molta repressió. Varen començar a expedientar a gent, que això volia dir que havien d'anar a estudiar a altres districtes universitaris. Per exemple, alguns historiadors que conec o gent que estudiaven econòmiques varen tenir que anar a Bilbao. Es va arribar a perdre la matrícula col-lectivament, no sé si en el 66 o en el 67. El què passa és que la matrícula llavors era més barata; ara, comparativament els sous i els ingressos també eren bastant més baixos.

I també va començar una cosa que és que els universitaris, pel fet de ser universitaris, tenien, diguem-ne, com un cert privilegi en relació al servei militar. Per comptes d'anar-hi en el moment que tocava i fer els tretze, catorze o quinze mesos seguits, feien "milicias universitarias" a l'estiu. Per tant amb això et concedien una pròrroga. Al final d'aquestes milícies sorties alferes que era, crec, el grau màxim amb el que podies sortir fent això. Doncs llavors varen començar a eliminar les pròrrogues militars per als universitaris i per tant, si ja tenies l'edat, en el moment en què et tocava te n'anaves a fer el servei. I amb això varen fer desaparèixer... varen escapçar el moviment estudiantil. De tal manera que jo, al maig del 67 , crec que deuria ser, vaig ser enviat també al servei militar. Per tant jo era una mica més gran que la resta dels meus companys; és a dir, hi havia dos anys i 


\section{perifèria}

Número 20(2), diciembre 2015

www.periferia.name

mig o tres en relació als que eren del mateix curs meu, no? I com a resultat de tota aquesta desaparició de gent, doncs, en els cursos els líders anaven canviant molt ràpidament. Per això jo vaig passar de delegat del meu curs probablement a delegat de Facultat. Vaig començar com a delegat d'informació, perquè l'aparell d'informació era molt important. I en aquella època no hi havia ni fotocopiadores... Tot eren ciclostils, no sé si n'heu sentit a parlar del ciclostil. És una cosa molt manual i a més era molt perillosa, perquè tota la propaganda s'havia de fer en un lloc i distribuir en cotxes. Tenien que arribar totes les declaracions de la Junta de Delegats de la Universitat, les declaracions de cada facultat tenien que arribar a tots els cursos... $i$ ho fèiem en paper. I per tant tenia que haver-hi una infraestructura i els delegats i subdelegats d'informació eren molt importants.

Jo recordo que al 64-65 vaig estudiar força... coses inútils [riu]. Els professors eren... alguns d'ells, eren diguem-ne molt pintorescos, de l'època franquista... Un d'ells era un professor que ensenyava grec però no ensenyava res (un senyor que era capellà, era canonge). Un dia va arribar a classe i va dir, amb una veu que tenia molt així: "Recen, recen porque su Santidad ha perdido el juicio. Ha devuelto la enseña que los cristianos quitaron a los turcos en la batalla de la Lepanto... ila ha devuelto!" [riures]. I altres històries d'aquestes. Bé, el curs del 65-66 va ser l'any de la meva implicació més directa fins al maig del 67, que vaig haver de desaparèixer. Fent un servei militar d'uns tretze mesos. En definitiva, crec que la meva fase política va ser com a resultat de les circumstàncies; no venia d'una preparació intel·lectual. 


\section{perifèria}

Número 20(2), diciembre 2015

www.periferia.name

Sí que em va proporcionar una preocupació, un interès per la realitat. També per relacionar el que passava a nivell local amb un nivell més general amb la política repressiva de l'Estat. S'analitzava molt el que estava passant. En aquell moment també va haver-hi manifestacions d'estudiants i obrers. Després d'això, aquí les polítiques dels partits també hi va incidir i bé, ... es va parar. Però jo crec... -ho dic a posteriori, ho he escrit en aquest paper, podeu trobar-ho més concisament-, crec que aquesta fase política em va donar un interès per la realitat. Una realitat que no tocàvem de prop, no?

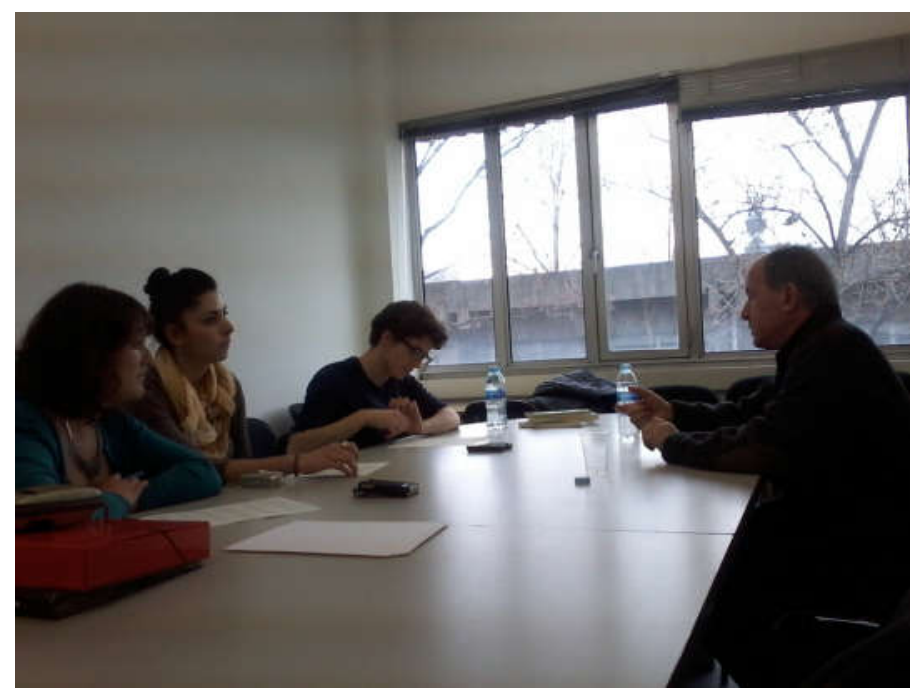

P: Vostè va començar la disciplina quan l'Estat espanyol encara estava en procés d'institucionalització. Per una banda hi havia el corrent de I'antropologia cultural, que identifiquem amb en Claudi Esteva Fabregat; i per altra banda hi havia l'antropologia social per part de Carmelo Lisón Tolosana. Malgrat que Claudi Esteva va dirigir 


\section{perifèria}

Número 20(2), diciembre 2015

www.periferia.name

la seva tesi que va presentar el 1974, sobre "Diferenciación y estratificación sociocultural en el campo español: la Vega alta del Segura (Calasparra), en aquest treball està molt influenciat per I'antropologia social britànica. La pregunta era: per quina raó es va acabar decantant per aquesta perspectiva?

F: Bé... a veure. El meu treball de camp inicialment volia ser un estudi de I'emigració murciana a Catalunya. Perquè ja en aquesta època, en els mitjans nacionalistes catalans el problema era la immigració i el seu impacte en la identitat catalana. En altres mitjans, hem de confessar-ho, els problemes diguem-ne més importants eren la democratització del país. Estem parlant de que Franco va morir al novembre de 1975. Per tant, el sistema era el mateix. No hi havia dret de lliure expressió, no hi havia dret d'associació, no hi havia dret de reunió... Bé, no hi havia els drets fonamentals. Hi havia un tribunal a Madrid, que no era I'Audiència, que era el TOP. El TOP era el Tribunal de Orden Público, perquè totes aquestes manifestacions era infringiment de l'ordre públic. Tres persones a l'acera eren una multitud i els polis [la policía] deien: "Disuélvanse! Disuélvanse!".

Però també hem de confessar que en els mitjans, diguem-ne nacionalistes que potser no eren hegemònics en aquell moment-, el problema de la migració era el gran problema. Era l'emigració del camp a la ciutat, que es va donar a Catalunya però també es va donar en altres parts... Vull dir que no era només de fora, també era interna, no? Jo vaig pensar que un tema

\footnotetext{
${ }^{5}$ La tesi fou presentada el 27 de setembre de 1974 a la Facultat de Geografia i Història de la Universitat de Barcelona.
} 


\section{perifèria}

Número 20(2), diciembre 2015

www.periferia.name

d'estudi seria la integració (que tampoc sabia què volia dir) dels murcians a Catalunya. I vaig buscar una àrea bastant petita perquè fos adequada per als procediments antropològics, que era uns pobles del Maresme. Concretament entre Premià de Mar i Vilassar de Dalt. Allà hi ha un barri, que és el barri Cotet, que és un barri d'emigrants. I vaig anar allà, a l'ajuntament de Vilassar i vaig estar mirant el cens i vaig veure d'on venia aquesta gent, no? I la meva idea va ser de fer un viatge a Múrcia per conèixer millor aquella realitat. En aquell moment la informació era difícil; els estudis històrics, sociològics i demogràfics sobre certes àrees eren escassos. Jo no els coneixia i no hi havia Internet. No era fàcil de trobar informació. Jo no havia estat mai a Múrcia perquè a la meva època es viatjava molt menys. Jo havia viatjat molt poc... Només havia fet una excursió per Espanya perquè als maristes on vaig estudiar el "preuniversitari" (el què es deia el Preu abans), doncs ens varen portar a final de curs a una cosa d'aquestes típiques i tòpiques: a les falles de València, las Casas colgantes de Cuenca, Madrid, El Escorial, el Valle de los Caídos i el Monasterio de Piedra de Zaragoza... I tornar cap a casa.

I després estudiant a la universitat sí que m'havia mogut, precisament per la connexió entre el sindicat local (SDEUB) i les universitats. Perquè en el 67 van estar parades (en vaga) totes les universitats espanyoles, fins i tot les més recents que s'havien creat a llocs que no tenien tradició. Llavors la connexió entre universitats era molt forta... Jo havia viatjat una vegada al País Basc i havia viatjat una altra vegada a València però era només per raons de feina [riu]; per tant, no havia fet turisme. 


\section{perifèria}

Número 20(2), diciembre 2015

www.periferia.name

Però jo no havia estat mai a Múrcia i volia anar-hi per veure com era el paisatge, la cultura i veure quines eren les raons per les que aquesta gent havia marxat. Els murcians eren un grup de gent que tenien ja una tradició d'emigració a Catalunya; vull dir que els que jo volia estudiar als anys 70 eren recents però hi havia hagut una migració murciana que ja venia de molt abans, no? I quan vaig arribar allà em vaig adonar que hi havia unes altres realitats. Jo no sé si pensava si eren exòtics o no perquè no ho puc reconstruir. Però era la visió d'un que no ha estat mai més enllà de casa seva.

I llavors vaig canviar. Potser aquí està això que deies de la presència de l'antropologia social. Perquè pel concepte d'integració, si parles de cultura (encara que no sàpigues ben bé què és), potser el terme cultura, etnicitat, va millor. Però si et trobes amb una societat molt estratificada, amb jornalers, amb pagesos petits, més grans, amb grans propietaris, amb professionals... Et trobes amb una estructura $a m b$ divisions entre la gent del poble i la gent del camp... No sé, aquí encaixa molt més fàcilment el concepte d'estructura social, estratificació, etcètera, no? Jo portava, quan vaig anar a Murcia al desembre del 71, el Ilibre del Carmelo Lisón Tolosana que s'havia publicat: La antropologia cultural de Galicia. Que encara que es digui cultural, de fet a dintre és clar que l'estructura que ell estudia és social: tot aquell conjunt de les aldees, les parròquies, els municipis... Tot allò és una versió de l'estructura social.

Potser també hi ha una cosa aquí, i no és cap demèrit però clar, Claudi Esteva no havia escrit cap monografia... Per tant, els models que tenia eren d'antropologia social britànica... Jo havia llegit el llibre de Pitt-Rivers The 


\section{perifèria}

Número 20(2), diciembre 2015

www.periferia.name

People of the Sierra amb una edició anterior de Grijalbo, amb una traducció infecta però bé... [riures] Sí, i tant infecta! Perquè al capítol final, per exemple, parla de l'anarquisme i de la vaga general. I el traductor va traduir "vaga general" en majúscules per "el General Strike". Strike amb anglès és vaga, no? Amb lo qual... [riem tots] ...tu llegies allò...! Però bé, la prolongació final del seu argument era la contraposició de dues estructures que estan en oposició. El model de Pitt-Rivers és també estructura social. I algun altre que havíem llegit... Hi havia el del Lisón i després hi havia també aquest sociòleg, Victor Pérez Díaz, que havia escrit un llibre que es diu Estructura social del campo y éxodo rural. ${ }^{6}$ De fet, és com l'estudi d'un petitíssim poble de Castella. I jo, un dels problemes que vaig tenir és que vaig anar a parar a un poble molt gran per l'estàndard, diguem-ne, dels altres pobles.

\section{P: En el seu text Las conversaciones y los días en Calasparra: Diario etnográfico 1971-74, fa un comentari sobre la dèbil institucionalització de la disciplina on diu: "Más que seguir un camino trillado, había que buscar por necesidad un camino propio". Com definiria aquest camí pioner?}

F: Bé, això potser és una mica... exagerat no, però és evident que en aquell moment els models que hi havia... Jo al Claudi Esteva va ser per atzar que el vaig arribar a conèixer. I de fet, ell és el que em va donar l'empenta definitiva per fer antropologia. Ell a la Universitat de Barcelona, juntament amb alguns altres professors, destacava: pel seu caràcter, la seva

\footnotetext{
${ }^{6}$ Victor Pérez Díaz, Estructura social del campo y éxodo rural, Madrid: Tecnos, 1966.
} 


\section{perifèria}

Número 20(2), diciembre 2015

www.periferia.name

personalitat, per les coses que ensenyava... Eren coses que aquí no es veien. Jo que havia estudiat filosofia tomista $i$ coses estranyes... I a psicologia no sé què del comportament de les formigues... I és clar, ell parlava de cultura, parlava de moltes coses i era molt atractiu. I ens va recomanar una sèrie de lectures que després, amb una sèrie de gent vàrem fer com un seminari per a nosaltres: amb en Jesús Contreras, en Joan Prat, la Montserrat Camps, que és germana de la Victòria Camps, algun altre noi que ja no recordo... Vàrem començar aquest seminari de lectures abans que comencés el curs, perquè jo el vaig conèixer abans de que comencés aquell curs. I aleshores ens va recomanar llibres que s'havien traduït. Bàsicament del Fondo de Cultura Económica: Herskovits, El hombre y sus obras (que és de la tradició de l'antropologia cultural de Boas, deixeble dels deixebles de Boas, com Kroeber); Clyde Kluckhohn (que també tenia un text més breu sobre antropologia d'aquesta línia al Breviarios); Ralph Linton (que aquest era nordamericà però que havia rebut la influència britànica perquè Radcliffe-Brown havia estat ensenyant una època crec que a Xicago), ...

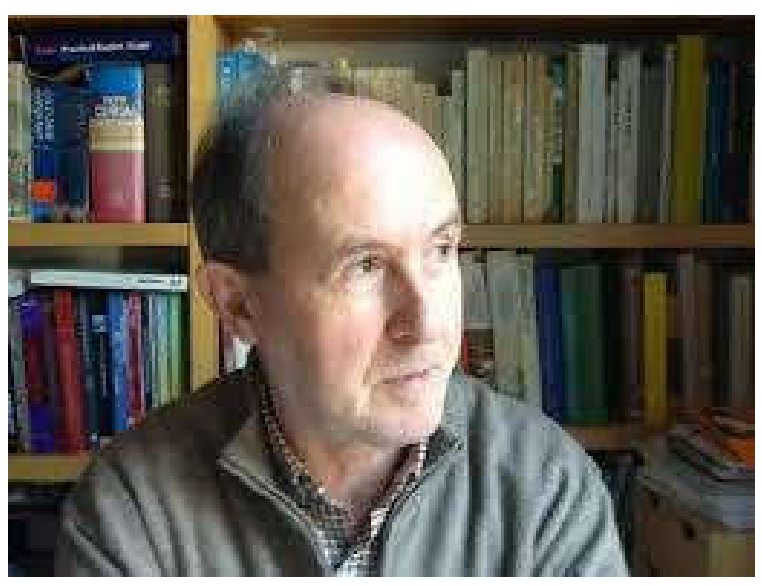




\section{perifèria}

Número 20(2), diciembre 2015

www.periferia.name

També un llibre sobre Cultura i Personalitat que aquesta és una de les coses que li interessaven a Claudi Esteva. Jo com que no sabia de psicoanàlisi i no m'interessava, aquesta part no era una de les coses que m'atragués particularment. Però un dels llibres era Antropología Social que són unes xerrades que Evans Prittchard va fer a la BBC i és un llibre encara molt útil. Unes xerrades que va publicar una editorial estrangera, Nueva Visión, una editorial argentina que havia publicat la traducció d'aquestes xerrades. I ell fa un panorama de l'antropologia social molt breu, molt eficaç, molt interessant, no?

Una cosa que ha estat molt important per mi han estat les dues etapes de treball de camp. En Claudi Esteva va organitzar (ja ho havia fet a Madrid això) unes visites o estada en el Pirineu d'Osca, a Bielsa, a San Juan de Plan. Ens hi va portar una setmana, vuit o deu dies, en un moment a I'hivern i després un altre a l'estiu. I això per mi va ser molt important.

I bé, quan vaig aterrar a Murcia, ja vaig veure que el tema de la integració era molt difícil de fer. Primer perquè el poble era molt gran. Jo vaig anar a parar a aquell poble perquè m'era igual qualsevol i era l'únic lloc del que tenia un contacte, que m'havia indicat el professor Horacio Capel; i per tant podia anar i dir: "Miri, vengo de parte de fulano de tal". I el vaig trobar, no?, i em vaig quedar allà. I llavors ja no vaig poder elegir en funció de la demografia o fer una selecció en funció d'una sèrie de criteris... Jo només volia submergir-me una mica en la realitat per tenir matèria de què parlar amb la gent de Múrcia d'aquí a Catalunya, perquè quan em parlessin de certes coses saber de què em parlaven... 


\section{perifèria}

Número 20(2), diciembre 2015

www.periferia.name

Aleshores, el què jo volia dir sobre això de "había que buscar por necesidad un camino propio" és que el què va ser molt important va ser el treball de camp. Jo crec que sempre he imaginat que la meva trajectòria era lineal..., potser no ho és, però crec que els treballs de camp m'han donat l'empenta per a veure els temes que he anat treballant.

Jo he fet tres treballs de camp; no tots exitosos però en tres moments diferents. El primer a Calasparra del 1971 fins el 74; dos dies del 75 (perquè jo llavors vaig deixar la Universitat de Barcelona i vaig estar treballant a Madrid en una cosa que no era la universitat); i vaig tornar a Calasparra el febrer de 1976 i vaig estar-hi fins el setembre. I al setembre del 1976 vaig entrar de professor a la Universitat Autònoma de Barcelona $(\mathrm{UAB})$, on hi vaig estar fins a tornar a la Universitat de Barcelona. Bé, el penúltim any vaig estar fora: el 1987-88 vaig estar a Almería en un treball de camp amb finançament nord-americà. La universitat et dóna una part del sou i amb la resta del sou contracten algú perquè et supleixi la teva docència. I quan vaig tornar al 1988-89 vaig fer l'últim any de classes a la UAB. Ja el 1989 vaig fer la oposició i al novembre del 89 vaig entrar a com a professor la Universitat de Barcelona, no?

Com us deia, el segon treball de camp va ser del juny del 1987 al setembre del 1988 a Almería; que va ser un treball intensiu, tot seguit, va ser quasi un suïcidi.. . [riu] I després el tercer treball de camp va ser del maig del 2002 fins el 2010 aproximadament, a temps parcial, a la Vall de La Vansa i Tuixent, a l'Alt Urgell.

Aleshores, cada un dels treballs de camp m'ha portat a temes, no? Per exemple, el primer treball a Calasparra em va portar a una investigació que, 


\section{perifèria}

Número 20(2), diciembre 2015

www.periferia.name

de fet, va ser l'objecte del segon treball a Almería, encara que havien passat 10 anys entre el 1976 i el 1987... El tema era la institució de "llevarse a la novia". 7 Hi vaig aplicar els conceptes de ritus de pas, matrimoni consuetudinari, estratègia matrimonial i institució. Abans vaig fer una sèrie d'investigacions per enquesta i algunes sobre el terreny (a Múrcia, Andalusia i àrees properes) sobre la importància del "llevarse a la novia" com a indicador de desigualtat i de diferenciació cultural. Llavors volia fer un treball d'extensió d'això, de comparació. És a dir, de posar-ho en un marc més universal, de relacionar-ho més directament amb l'acció de l'Església, de l'Estat, amb l'estructura social, obtenir més dades demogràfiques... Això em va portar al segon treball a Almería, que va estar inicialment centrat en això: en aprofundir en un poble molt més petit, amb molta documentació demogràfica, etc... Com a resultat d'això, que no va sortir del tot bé (o en tot cas no va resultar com s'esperava), en van sortir tota una sèrie de temes. Com per exemple, el tema de la importància de la relació entre Antropologia i Literatura; d'aquí va sortir el meu treball sobre Lorca. $^{8}$ I d'aquí també va sortir el tema de la procreació, de la importància de la procreació, de les concepcions de gènere i, en particular, de la masculinitat en un ampli vano de contextos i rols. ${ }^{9}$ I per la procreació vaig

\footnotetext{
7 Joan Frigolé i Reixach, Llevarse a la novia. Matrimonios consuetudinarios en Murcia y Andalucía, Bellaterra: Publicacions UAB, 1984.

8 Joan Frigolé i Reixach, Un etnólogo en el teatro. Ensayo antropológico sobre Frederico García Lorca, Barcelona: Muchnik, 1995.

9 Joan Frigolé i Reixach, Un hombre. Clase, cultura y género en el relato de un trabajador, Barcelona: Muchnik, 1998.
} 


\section{perifèria}

Número 20(2), diciembre 2015

www.periferia.name

anar a parar bastant més tard al tema del genocidi, a escriure una sèrie de textos sobre genocidi, no ${ }^{10}$ Primer vaig escriure el llibre i després vaig crear el curs... [riu] I després vaig intentar prolongar aquesta onada una mica més, vaig escriure alguns textos ${ }^{11}$ més fins que ja... [riu] Bé, ja ho sabeu, després la universitat et reclama, has de fer altres coses, hi ha les classes, etc... Però bé, vaig crear el curs d'Antropologia del Genocidi, que el vaig donar fins que em vaig prejubilar als 67 anys, l'any 2010.

Llavors comença el treball de camp a I'Alt Urgell i trobo a posteriori que I'Alt Urgell i Almería tenien bastantes afinitats, no ho havia vist d'entrada. Dos llocs de muntanya en què l'agricultura i la ramaderia pràcticament han desaparegut. I que en un han inventat una nova manera de viure a través de la patrimonialització, el turisme, etc..; i en l'altre, dalt de les muntanyes d'Almería (almenys en aquell moment, eh) que continua semiàrid, amb problemes d'aigua etc..., no tenien elements patrimonials. Però les agricultures i l'estructura social, els moviments de la gent, eren similars. Els de la Vall de La Vansa a I'hivern se n'anaven pel món i els d'Almería d'allà de les muntanyes se'n anaven (ells deien "a Andalucía") a les mates a Córdoba. Les mates és l'agricultura de "tala i crema", és anar a tallar la vegetació, artigar per fer terres de cultiu. I anaven també durant I'hivern, uns viatges llarguíssims en una època en què les comunicacions eren molt difícils... Hi havia moltes similituds.

\footnotetext{
10 Joan Frigolé i Reixach, Cultura y genocidio, Barcelona: UB, 2003.

11 Joan Frigolé, "The Extreme Faces of Power: Genocide, Massacre and Ethnic Cleansing", Kula 1(2), 2008:20-28. Joan Frigolé, "Genocidio y procreación", Alteridades 36, 2009:95-105.
} 


\section{perifèria}

Número 20(2), diciembre 2015

$\underline{w w w . p e r i f e r i a . n a m e}$

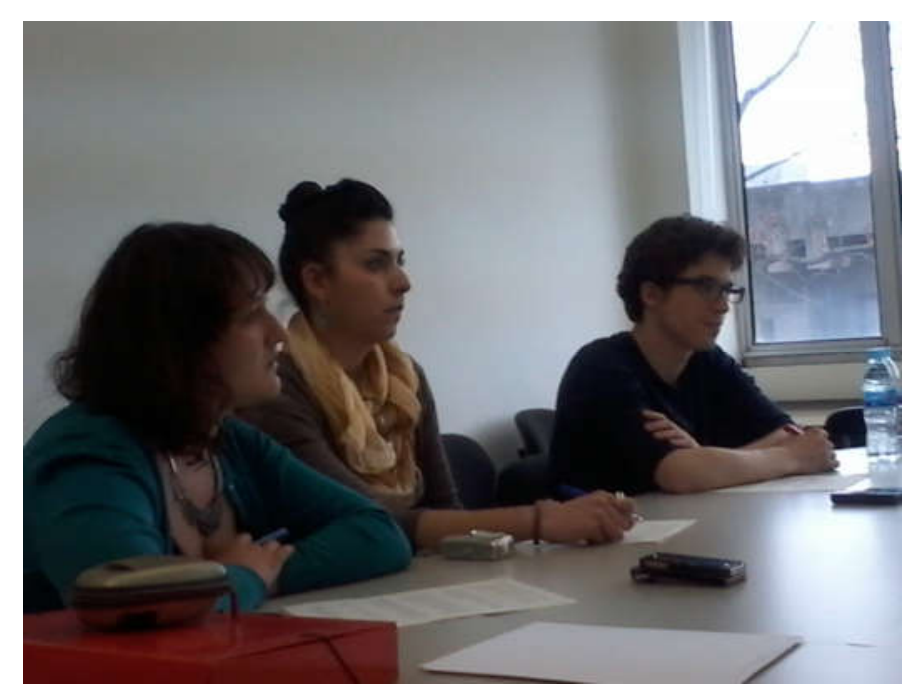

I des de d'aquí, del treball de la Vall de La Vansa sobre la patrimonialització de les trementinaires, ${ }^{12} \mathrm{~m}^{\prime}$ han sortit alguns altres temes que estan més o menys en procés, eh! Com per exemple la mateixa importància de la patrimonialització, la importància de la mercantilització d'allò autèntic, la importància dels béns singulars. I alguns altres que d'entrada jo no havia pensat que serien objecte de la meva consideració. Però vull dir que cada treball de camp ha presentat una sèrie de camins que es desvien. Que alguns, el de la Literatura i Antropologia I'he seguit una mica, no molt. Però tots han donat un llibre i varis articles. No era que jo volgués ser especialista d'això però és que el treball de camp d'alguna manera m'ha empès cap a aquests temes, no?

\footnotetext{
12 Joan Frigolé i Reixach, Dones que anaven pel món. estudi etnogràfic de les trementinaires de la Vall de la Vansa i Tuixent (Alt Urgell), Barcelona: Departament de cultura, 2005.
} 


\section{perifèria}

Número 20(2), diciembre 2015

$\underline{w w w . p e r i f e r i a . n a m e}$

Aquí tens la resposta de perquè deia que havia de buscar un camí. Suposo que vosaltres que estudieu a la universitat també haureu de buscar un camí i suposo que el treball de camp us ajudarà a concretar molt, no? El treball de camp, com els primers que vaig fer, van ser molt importants perquè et donen una dimensió real del què és la solitud. Bé, un dels meus companys, en Jesús Contreras, sempre diu que per ell va ser com un trauma la seva primera estada de camp com a estudiant de Claudi Esteva. Sí, és que ho és, és complicat, eh? I un busca a qui sigui per parlar, per entrevistar!!! I si no el troba, què fa en aquests pobles de muntanya petits, tancats, en època d'hivern precisament? Jo crec que sí que és complicat al principi. I després ja comences a llegir coses, a buscar, a filtrar la bibliografia, eh?

\section{P: Llavors consideraria que és el treball de camp de les fites que més I'han marcat com antropòleg?}

F: Jo diria que el treball de camp ha estat molt important, sí. Jo diria que sí. Perquè ja sabeu que hi ha gent i moments que desvaloritzen el treball de camp... Jo parlo d'ara des de la meva perspectiva i a demés potser fins i tot vist a posteriori potser he estat una mica atrevit, eh? [riu] Però jo començo a fer un treball de camp al desembre abans de Nadal del 1971, d'acord? Si mireu la introducció en els meus diaris de camp, veureu que a la tardor del 1973 es va fer la $1^{\text {a }}$ Reunió d'Antropòlegs Espanyols a Sevilla. La primera reunió, eh! Això hi ha unes actes que deuen estar a la biblioteca. ${ }^{13}$ L'editor era un professor catedràtic d'etnohistòria, Alfredo Jiménez Núñez, que era

\footnotetext{
13 Alfredo Jiménez Núñez, Actas de la Primera Reunión de Antropólogos Españoles: Actas, Comunicaciones, documentación, Sevilla: Universidad de Sevilla, 1975.
} 


\section{perifèria}

Número 20(2), diciembre 2015

www.periferia.name

director de departament de Sevilla. En aquesta reunió veureu que hi havia antropòlegs, específicament, però també hi va haver altra gent: historiadors d'Amèrica, arqueòlegs i antropòlegs físics. A la pràctica hi va haver aquestes quatre branques o disciplines, no? I en aquesta reunió de Sevilla jo hi vaig presentar el primer text. I això va ser possible per aquest treball de camp que havia fet; que no era molt, però sense això aquest text no hauria pogut presentar-lo.

I us diré una altra cosa: al 1975 vaig publicar un article sobre la creació i evolució d'una cooperativa agrícola. ${ }^{14} D^{\prime}$ entrada jo mai hauria pensat d'investigar una cosa de la qual no en tenia ni idea; I'economia no ha estat gaire el meu fort. Per què la vaig arribar a estudiar? També va ser pel treball de camp. Jo ho vaig escriure perquè la cooperativa agrícola estava molt condicionada pel context jurídic. El 1942 l'Estat dicta una llei de cooperació que anul·la l'anterior llei de la República. Les cooperatives en principi (sobre la llei internacional) són autònomes. En canvi l'Estat franquista les situa dintre de l'organització sindical. Per tant, són també organismes que estan tutelats per I'organització sindical, la Central Nacional Sindicalista que hem dit abans, la CNS. Per tant, és una acció política. És a dir, a Murcia com a moltes parts de l'estat Espanyol, no hi havia tradició cooperativista. El cooperativisme estava relacionat amb el catolicisme social i amb l'anarquisme: n’hi havia al País Basc, a Navarra, als Pirineus, a Barcelona... però a Alacant, Murcia i molts llocs no n'hi havia. I això es crea

\footnotetext{
14 Frigolé, "Creación y evolución de una cooperativa agrícola en la Vega Alta del Segura desde 1962 a 1974", Revista de Estudios Sociales 14-15, 1975, pp-167-200.
} 


\section{perifèria \\ Número 20(2), diciembre 2015 \\ www.periferia.name}

també com a resposta política als problemes del camp. En aquesta època les consignes del Partit Comunista eren "la tierra para el que la trabaja". Es parlava molt de la reforma agrària (encara que poc) perquè és el que va quedar pendent de l'època de la República. L'Estat, davant dels problemes del camp (que s'aguditzen per tota I'emigració que drena una mà d'obra barata i fa que pugin els preus del treball quan a més no estem a la Comunitat Europea) i de la demonització de l'intermediari, presenta la cooperativa com a solució, per evitar les demandes comunistes o anarquistes. A l'any 1970 hi havia 7.000 cooperatives agrícoles.

Aleshores aquí hi havia molta política: hi havia un context i després hi havia l'estructura social. Els propietaris s'havien posat a la cooperativa, I'alcalde, el governador civil..., perquè era un mandat polític interessat. En fi, jo vaig arribar a la conclusió que si no investigava la cooperativa, si no m'hi ficava (perquè em feia molta mandra), no acabaria d'entendre aquesta dinàmica a nivell local, no? Faltaria una peça d'un puzle en aquesta relació entre les classes, el poder entre elles i tot plegat. I això ho vaig publicar al 1975. O sigui que el treball de camp, que no era molt, em va fer avançar bastant ràpidament. Perquè és clar, et dóna uns objectius, uns problemes, unes dades, uns desafiaments i bé, - si tens temps! [riu] - doncs els has de respondre, no?

\section{P: En tots els treballs que ha publicat tracta el tema de l'adaptació a la societat i els canvis polítics i econòmics, entre d'altres temes...}

F: Bé, al llibre del genocidi hi vaig arribar a través de la importància de la procreació. Aquest és un fil que vaig estirar a partir d'un llibre que a mi em va marcar molt, d'un autora que a més la vaig conèixer. Jo quan al 1989 


\section{perifèria}

Número 20(2), diciembre 2015

www.periferia.name

vaig deixar la Universitat Autònoma i vaig guanyar la plaça de catedràtic a la Universitat de Barcelona, vaig anar dos mesos i mig a Stanford. Perquè el meu treball d'Almeria I'havia fet amb col-laboració i amb diners nordamericans d'uns antropòlegs de Stanford, el George i la Jane Collier que són uns antropòlegs molt destacats. I llavors, allà vaig conèixer a una professora que és Carol Delaney, una senyora que va estudiar ja gran i que va fer una monografia sobre un poble d'Anatòlia, a Turquia, que es diu The seed and the soil ("la llavor i la terra") sobre les concepcions de procreació dels pagesos en aquesta societat. És d'aquesta monografia que vaig agafar la idea o la importància de les idees sobre procreació. I vaig aplicar-ho a l'etnologia del sud d'Europa i també d'alguna part del Mediterrani, perquè molts autors parlen, per exemple, de sexualitat però no de procreació. ${ }^{15}$ Això ja m'ho havia trobat jo en el treball de camp. Quan a nivell local la classe mitjana explica perquè algú "se lleva a la novia" o "una se va con el novio", poden fer una referència o al-lusió a la sexualitat desordenada. Et poden dir frases típiques que ara no repeteixo. Aleshores vaig fer com una espècie de revisió de les explicacions fetes en termes de sexualitat que jo crec que s'entenen més en termes de procreació. I després, quan vaig treballar la Yerma de Lorca vaig també aplicar aquesta visió. Els crítics literaris solien aplicar-hi (a través de la psicoanàlisi o d'altres models) també la idea de sexualitat: de repressió sexual, de fal.lus i de no sé què més... Però, jo entenc que Yerma és el paradigma d'un model de procreació, és un problema de procreació, eh? Lorca construeix un model de

\footnotetext{
15 Frigolé, "Procreation and Its Implication for Gender, Marriage and Family in European Rural Ethnography", Anthropological Quarterly, 71(1), 1998:32-40.
} 


\section{perifèria}

Número 20(2), diciembre 2015

$\underline{w w w . p e r i f e r i a . n a m e}$

procreació al voltant de les metàfores llavor-camp, tensa fins a l'extrem la seva lògica interna i el resultat és un gran dramatisme en les identitats de gènere.

I llavors va ser a partir d'aquí estirant (no puc reconstruir en aquest moment com hi vaig arribar) que vaig anar a parar al tema del genocidi. Crec que és un tema que els antropòlegs I'han estudiat poc, perquè han estudiat I'etnocidi. I l'etnocidi és en termes culturals, la pèrdua de la cultura, però el genocidi és l'aniquilació. Jo vaig pensar que la idea aquesta procreació, que té a veure amb la cultura, podia explicar almenys algunes coses del genocidi. El mètode de procreació és un component essencial de la cultura que identifica als membres d'un estat-nació, la principal arena del genocidi contemporani. A la definició oficial de genocidi de Lemkin, en quan als supòsits, $n$ 'hi ha dos que fan referencia a la procreació. Jo crec que l'èmfasi en la procreació explica millor el genocidi. Perquè una cosa és la massacre, d'acord. Però el genocidi és quan vols exterminar l'arrel. Una altra cosa és que sigui possible, però la intenció hi és. I la planificació també hi és. Jo vaig arribar al tema aquest del genocidi no tant en termes de política sinó agafant el concepte de cultura i evidentment reduint-lo, es clar. Reduint-lo bàsicament a les idees sobre procreació, i la seva connexió amb la religió (la idea de Déu) i també la idea de grup ètnic. Aquestes tres coses és el que jo vaig entendre per cultura, però amb les idees de procreació $\mathrm{i}$ I'acció contra la procreació com un element central: extermini de famílies senceres, atac i destrucció dels òrgans de procreació, extermini, rapte, dispersió i canvi de la identitat dels nens i nenes. Tot això és l'expressió més explícita de la intencionalitat genocida. 


\section{perifèria}

Número 20(2), diciembre 2015

www.periferia.name

P: Pel què al seu treball Dones que anaven pel món, sabem que va ser realitzat per un encàrrec del Museu de les Trementinaires de Tuixent I'any 2002, que donà lloc a la publicació al 2005. Aquest estudi etnogràfic és una aproximació al tema de la patrimonialització $\mathbf{i}$ el procés de canvi. El seu interès pel patrimoni $\mathbf{i}$ els treballs que ha realitzat després són arrel d'aquest treball 0 venien d'abans?

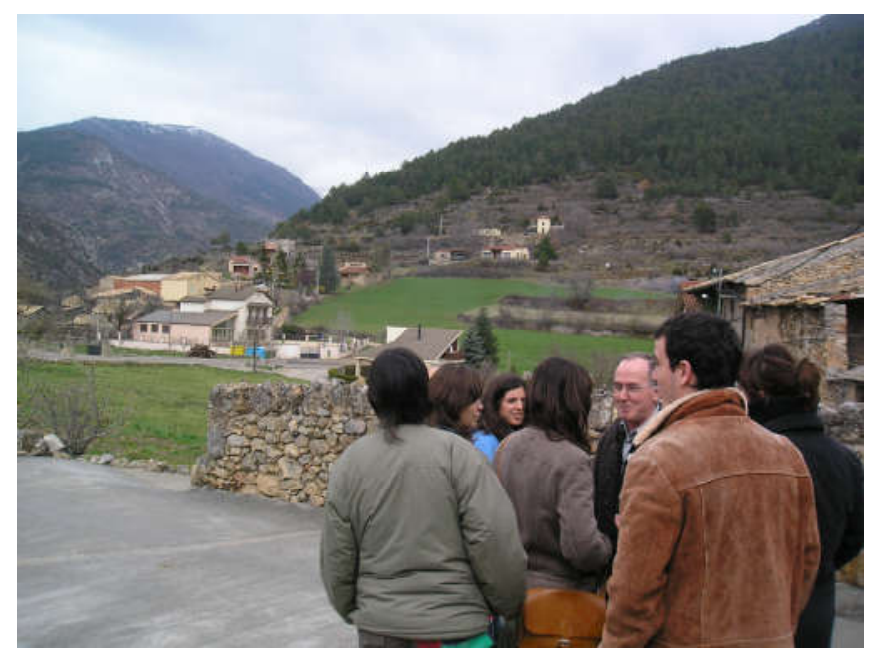

Joan Frigolé amb un grup d'alumnes de pràctiques de camp a Tuixent (L'Alt Urgell) al 2007

(fotografia de l'autor)

F: No, això va començar també per atzar [riu]. Jo mai havia pensat fer un treball de camp a Catalunya. A demés, segons I'escola clàssica, els treballs de camp boasians, ja ho deia l'Esteva, s'han de fer fora del teu Iloc [riu] Després això ha canviat $\mathrm{i}$ tal, però jo no pensava treballar a Catalunya $\mathrm{i}$ potser no pensava ni fer un tercer treball de camp... No ho sé, és igual. En tot cas, la qüestió de la patrimonialització comença aquí perquè calia d'alguna manera buscar més informació per potenciar aquell museu. Jo no 


\section{perifèria \\ Número 20(2), diciembre 2015 \\ www.periferia.name}

sé si al començament o ja en el procés d'investigació vaig obrir més el focus i vaig pensar que calia tenir en compte dues coses. Per un costat, buscar i reconstruir el màxim de trajectòries específiques de les trementinaries (tenint en compte que moltes estaven mortes, però bé, fer-ho a través dels testimonis més propers). Per altra banda, no oblidar els canvis que s'estaven produint. La recerca sobre les trementinaires va acabar amb el llibre. La de les transformacions... ho he començat a treballar, he publicat alguns articles... però diguem-ne que encara falta treballar-hi. No sé si donarà peu a un llibre, això ja és una altra història, eh? Però sí que hi ha alguns textos que tracten d'aquestes transformacions.

\section{P: Pel què fa al seu llibre Un etnólogo en el teatro, publicat al 1995, vostè analitza l'obra de Lorca per extreure'n un coneixement etnogràfic. Els que volíem preguntar-li és: què hi fa realment un antropòleg al teatre? D'on sorgeix aquesta idea?}

F: A veure, no sé si és per treure'n un element etnogràfic sinó potser per aportar-li un element etnogràfic. La idea també és bastant simple. Jo a Lorca l'havia llegit ja de més jove, de fet a l'època universitària. Lorca per vosaltres ha de ser important però per mi era molt més important en aquella època. Estaven publicades les seves obres completes, això arribava. Però moltes de les interpretacions de Lorca són de psicoanàlisi. Hi havia una època que molts crítics literaris utilitzaven la psicoanàlisi. Jo vaig pensar que l'antropologia podia aportar alguna cosa a la interpretació, podia aportar elements teòrics i context etnogràfic. Encara que l'obra de Lorca no sigui etnogràfica, sí que tenim descripcions sobre maneres de casar-se, sobre valors, sobre conflictes, etc... El què jo creia és que analitzar a Lorca 


\section{perifèria \\ Número 20(2), diciembre 2015 \\ www.periferia.name}

o analitzar una obra literària amb els alumnes podia ser una manera de fer etnografia. No és com fer un treball de camp, però moltes vegades els alumnes no poden fer experiències de treball de camp. Però potser poden analitzar algunes obres - i les de Lorca crec que s'hi presten, més que altres-, com si fossin una realitat. Com si fossin, perquè no ho és. Per tant, si acceptem aquest "com si fossin la realitat" li podríem aplicar els nostres instruments conceptuals, el que cadascú conegui en termes de teoria i el que cadascú conegui en termes d'etnografia. Perquè de dones infèrtils n'hi ha a la literatura: tenen un estatus molt baix $i$ en certes cultures farien el que sigui per tenir un fill,...etc. En l'etnografia hi ha moltes informacions sobre idees de la procreació. I els crítics literaris que no tenien aquest bagatge no ho podien interpretar. Per exemple la idea aquesta del camp i la llavor, que si llegeixes Yerma amb ulls antropològics-etnogràfics és bastant evident. Els altres no la veuen. Hi veuen I'aigua, hi veuen la sorra, i no sé què, però no troben aquesta parella metafòrica que és central per entendreho.

\section{P: Canviant de tema, sabem que viatja bastant a Mèxic i volíem saber si ens pot explicar les seves estades allà i els paral-lelismes i diferències que hi ha entre l'antropologia mexicana i la d'aquí}

F: No, no puc explicar-t'ho. A Mèxic sóc un avi que es cuida dels seus néts. No tinc gaires contactes ni tampoc els busco. Si vols que t'expliqui una mica la meva vida te l'explicaré. Hi anem des del 2005, i ara des de cap aquí hi anem més sovint. Jo vaig començar els primers anys intentant fer alguns contactes a través d'un noi que havia estat alumne de la UB i meu. Vaig demanar una beca de la UB per aquests intercanvis curts amb la UNAM: la 


\section{perifèria}

Número 20(2), diciembre 2015

www.periferia.name

UNAM paga la alimentació i I'hotel i la UB et paga el viatge. Vaig anar-hi a fer un seminari de 18 hores, 15 dies, sobre genocidi precisament. Vaig donar una conferència a la Universitat Autónoma Metropolitana de Itzapalapa. I vaig donar un parell de conferències al Instituto de Investigaciones Antropológicas. I això són tots els meus contactes a Mèxic. No vol dir que més endavant no en pugui tenir més, però no tinc una visió gaire clara de l'antropologia mexicana respecte a l'espanyola. Ara que sóc allà llegeixo algunes coses d'allà, però més aviat coses d'alguns autors nord-americans o estrangers que els tradueixen a Fondo de Cultura Económica, alguna cosa recent. $\mathrm{O}$ alguna obra clàssica. Per exemple, aquest semestre passat vaig llegir una obra de Guillermo Bonfil Batalla que és precisament sobre el Yucatán, una monografia dels anys 60 que és sobre I'antropologia de la fam.

P: Més enllà de la seva obra etnogràfica i teòrica, $i$ aprofitant que va ser un dels membres fundadors de I'ICA (Institut Català d'Antropologia), l'any 1978, ens interessaria molt conèixer de primera mà com va sorgir aquesta institució i com van ser els seus inicis.

F: Aquesta institució va néixer per una necessitat de formació, era una qüestió de formació. Jo vaig estudiar filosofia. Jesús Contreras, que és una mica més jove que jo, va estudiar filosofia. Joan Prat, que també és més jove que jo, també va estudiar filosofia. Ara ja no parlo dels altres. L'ICA es va institucionalitzar l'any 1978, però va començar abans, sense seu, anant d'un lloc a l'altre, fent seminaris i fins i tot en cases particulars. Hi havia aquí a Espanya, a Madrid, un fill de l'Àngel Palerm, que va venir a donar 


\section{perifèria}

Número 20(2), diciembre 2015

www.periferia.name

seminaris. L'Àngel Palerm, que es va morir molt aviat, és un dels pares fundadors de I'antropologia mexicana, és una figura molt important. Col-laborador d'Eric Wolf, Murra, ... gent molt important li ha tingut un gran apreci. Va fundar el departament d'antropologia de la Universidad Iberoamericana, que és privada, però també va fundar a Itzapalapa el departament d'antropologia. Va ser molt important també la seva dona, que s'ha mort ara fa poc, Carmen Viqueira. Doncs Juan Vicente Palerm, el seu fill, estava a la universitat de Madrid en aquest departament d'Història, Arqueologia d'Amèrica i Etnologia. El 1973 ell ja estava allà. I va ser el qui va publicar, a través d'una revista també a ciclostil de la Universitat Complutense, les ponències dels antropòlegs de la $1^{\mathrm{a}}$ Reunión de Antropólogos Españoles. Ell tenia contactes amb gent, perquè el seu pare era una persona important. A través d'ell i a través d'altres - potser també de Josep Ramon Llobera, que no era membre del grup, però que hi havia contactes -, tota la gent que passava per aquí Barcelona que eren antropòlegs, els hi fèiem fer seminaris. Ignasi Terrades va estudiar a Manchester i llavors gent de Manchester també va passar per aquí, francesos... De fet va passar molta gent i alguns eren molt importants. No sé si els enteníem o no però... [riu] També va passar per aquí un dels editors del llibre Reinventing Anthropology. Va ser doncs una qüestió de necessitat i també de crear un espai neutre. L'ICA en aquell moment era un espai on, vinguessis d'on vinguessis, podies formar-ne part sense tenir en compte de quina universitat eres. 


\section{perifèria}

Número 20(2), diciembre 2015

www.periferia.name

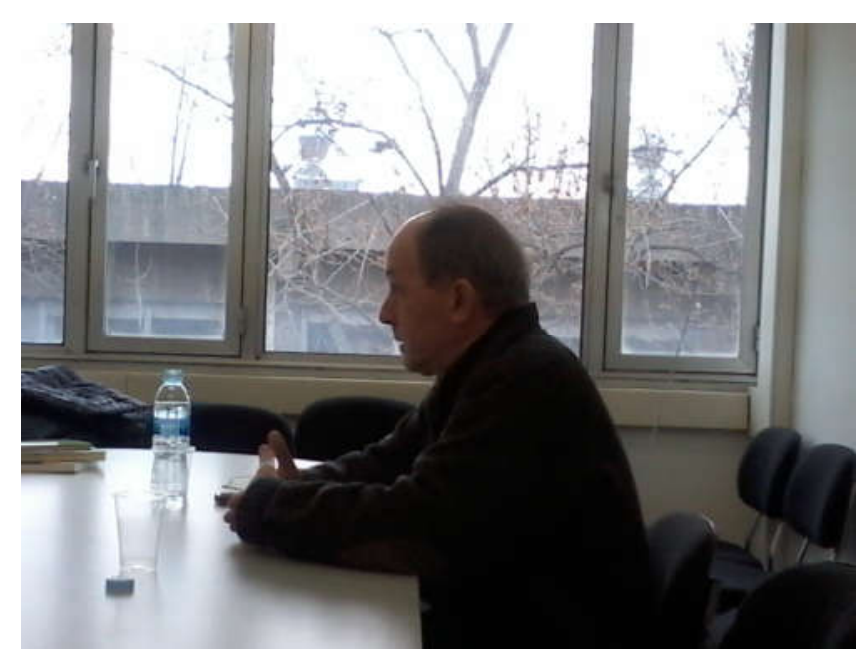

F: Finalment, malgrat que vostè ha estat i encara és professor vinculat principalment a la Universitat de Barcelona, com ens ha dit també va ser professor una temporada a la UAB, del 1976 al 1989, juntament amb en Ramón Valdés...

F: Sí, en Ramón Valdés és el que em va portar aquí. Ja ho he dit abans que en la meva trajectòria hi ha com a mínim dues persones importants. Una és Claudi Esteva, que el vaig trobar per atzar però que si no I'hagués trobat no hauria conegut I'antropologia. Si no l'hagués anat a veure i si ell no hagués estat una persona receptiva (pel seu caràcter o per la necessitat de créixer), doncs no s'hauria produït aquesta situació. I Ramón Valdés és el que em va recuperar d'alguna manera per a l'antropologia i li estic també molt agraït. És aquella mà que t'ajuda perquè et reorientis. Perquè jo vaig anar a treballar a Madrid en una cosa que no tenia res a veure amb l'antropologia i no sé com hauria seguit la meva vida. Ell em va oferir de venir a l'Autònoma. Si ell no m’hagués dit que tindria possibilitats d'entrar aquí... Encara que també hauria pogut passar que no s'hagués concretat, perquè 


\section{perifèria}

Número 20(2), diciembre 2015

www.periferia.name

les coses de les universitats no sempre són segures...! [riu] Però ell me la va oferir i va ser possible. I això també va ser molt important per a mi. Al Ramón el vaig conèixer en una altra circumstància institucional. Jo quan vaig estar a Madrid, vaig firmar una oposició a agregat que s'havia convocat - abans hi havia adjunts, agregats i catedràtics. Com que estava a Madrid, treballava en un Ministeri i tenia relativament temps la vaig preparar. Però no amb la idea de guanyar-la, jo no m'havia pas fet la il-lusió...! Però tu no sé si saps que abans - ara això ha canviat -, però abans a la meva època era qüestió de demanar tanda. Feies una oposició, que eren 7 exercicis, on calia donar-te a conèixer. No hi tenies res a guanyar però hi tenies molt a perdre, de manera que no t'ho podies agafar així a la lleugera, perquè no volies donar una mala imatge. Perquè potser el tribunal següent no era el mateix, però era una prova $i$ les proves s'han de superar. Com diu el Latour, si no se superen tenen efectes negatius. Llavors ell hi era, va conèixer la memòria que jo vaig presentar $\mathrm{i}$ allà vàrem confraternitzar, perquè vàrem passar un ritus de pas complicat. Era una setmana però molt intensa. Es passaven proves comunes i allà ens vam conèixer.

\section{P: Li volíem preguntar: com va ser la seva estada aquí a I'Autònoma?}

F: Bé, molt bé, va ser una estada molt normal. Jo vaig començar a donar classes aquí i vaig ampliar el meu repertori de classes. Jo ja havia donat classes a la Universitat de Barcelona però allà donava classes d'introducció. A la UB I'Esteva i la pròpia antropologia, com després també s'ha demostrat en altres llocs, van tenir molt atractiu. Per raons algunes fonamentals $i$ d'altres més aviat marginals, de poca consistència (motivacions que no són 


\section{perifèria}

Número 20(2), diciembre 2015

www.periferia.name

gaire interessants). Llavors hi havia molta gent i la tècnica que es va fer servir aquí (però també allà i a altres llocs) va ser créixer. Que era la manera de fer entrar personal. Llavors teníem molts grups d'introducció que donàvem a totes hores, no? Aquí a la UAB teníem menys gent per fer-ho, érem menys professors. Quan jo vaig arribar aquí hi havia el Ramón, hi havia I'Aurora González Echevarría i jo vaig ser el tercer. Hi havia una noia que era ajudanta que havia vingut d'Astúries que va marxar aquell mateix any que jo vaig arribar, no recordo el seu nom. No sé si havia fet la tesi...

Aquí a la UAB vaig donar assignatures més diverses. Vaig donar Etnologia de la Península Ibèrica i vaig donar molts anys Antropologia Política. I quan estava aquí portava gent com María Cátedra o Anne Cadoret, que és una antropòloga francesa; també Marc Abélès perquè el vaig ajudar a publicar el seu llibre sobre El lugar de la política i altra gent diversa. A través de I'ICA sempre que venia algú a Barcelona, procuràvem que vingués a donar una conferència. Recordo que vaig portar en John Victor Murra, I'especialista en el món andí, que era de l'àrea d'arqueologia, però amb orientació d'història i d'antropologia. I vam aprofitar que estava a Barcelona i va venir almenys dues vegades a fer conferències. No sé si I'heu llegit mai, hi ha un text molt interessant del Murra que és aquest de I'arxipèlag ecològic, però no pensat en sentit horitzontal sinó vertical. Deia que en els Andes hi havia com tot d'illes o nínxols ecològics ordenats verticalment. I el llibre sobre el sistema polític dels Inques, la importància dels teixits, de la reciprocitat... Són llibres 


\section{perifèria}

Número 20(2), diciembre 2015

$\underline{w w w . p e r i f e r i a . n a m e}$

molt interessants ${ }^{16}$. Jo recordo que cap al final vaig donar-li a l'Antropologia Política un contingut d'exemples d'Amèrica. I essent aquí vaig escriure i vaig publicar Llevarse a la novia, que va ser el meu primer llibre! [riu] I va ser aquí on vaig obtenir la meva titularitat, estant aquí, al 1984. També vaig fer aquesta segona recerca, aquest treball de camp, mentre estava aquí, amb els antropòlegs de Stanford. I el rector de la UAB que era Ramon Pasqual em va donar la llicència per poder anar a fer el treball de camp.

En fi, després va entrar al departament de la UAB Verena Stolcke i després, Teresa San Román i la família va anar creixent... I vaig marxar d'aquí el 1987 perquè vaig anar a Almería. I al 1989, abans de l'estiu vaig fer I'oposició a la UB, a continuació vaig anar a Stanford i vaig tornar per prendre possessió de la meva plaça a la UB el novembre del 1989.

\section{P: Bé, per part nostra no ens queda cap més pregunta. Moltes gràcies.}

F: Moltes gràcies a vosaltres!

\footnotetext{
16 John V. Murra, La organización económica del estado inca, México: Siglo XXI editores, 1978; y Formaciones económicas y política del mundo andino, Lima: Instituto de Estudios Peruanos, 1975.
} 